\title{
Analisis Efektivitas Katalis Fe/Zeolit Pada Cracking Minyak Jelantah Dalam Pembuatan Biofuel
}

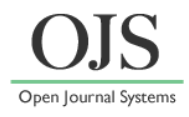

\author{
Lisa Adhani*, Reni Masrida, Nicky Putri Angela, Ridwan Rendi Nugroho \\ Program Studi Teknik Kimia, Fakutas Teknik, Universitas Bhayangkara Jakarta Raya \\ Jl. Raya Perjuangan Marga Mulya, Bekasi Utara 1714 \\ *Email: lisa.adhani@dsn.ubharajaya.ac.id
}

DOI: https://doi.org/10.33369/pendipa.4.1.7-11

\begin{abstract}
Petroleum fuels are increasingly limited in resources making the theme of sustainable energy one of the top issues in the world. Used cooking oil is non-edible and can even be said to be waste, so its use as a fuel does not compete with food oil and has a calorific value that is almost the same as conventional fuel. The cracking process is carried out using a Zeolite catalyst that has been impregnated with Fe. Fe/Zeolite catalyst variations are 1\%, 3\%, 5\%, and 7\%, with sizes 60, 80 and 100 mesh, while the temperature variations are $250^{\circ} \mathrm{C}$ and $350^{\circ} \mathrm{C}$. Whereas the dependent variable is time, which is 2 hours. The optimum results obtained with the greatest yield on the use of catalysts with a catalyst concentration of 3\%, catalyst size of 60 mesh and a temperature of $350^{\circ} \mathrm{C}$. The physical test carried out was a specific gravity test that was equal to 0.8241 at the optimum yield with a catalyst concentration of $3 \%$, and 1.0392 on the use of a catalyst with a concentration of 5\%. From the results of the GCMS test shows that the component that dominates the biofuel produced is gasoline seen from the C6 compound content of $17.2 \%$ and C8 of $13.7 \%$. It can be said that the largest amount is biogasoline shown by the presence of C5-C11 compounds of $72.4 \%$ than biodiesel indicated by the percentage of C12-C15 of $24.1 \%$.
\end{abstract}

Keywords: Biofuel; used cooking oil; catalytic cracking; Fe / zeolite.

\begin{abstract}
ABSTRAK
Bahan bakar minyak bumi yang semakin terbatas sumber dayanya menjadikan tema sustainable energy termasuk isu teratas di dunia. Didukung dengan kesadaran akan lingkungan bersih dan berkelanjutan yang semakin tinggi. Minyak jelantah bersifat non-edible bahkan dapat dikatakan limbah, sehingga penggunaannya sebagai bahan bakar tidak bersaing dengan minyak pangan dan memiliki nilai kalor yang hampir sama dengan bahan bakar konvensional. Proses catalytic cracking minyak jelantah telah dilakukan dalam penelitian ini. Proses cracking dilakukan menggunakan katalis Zeolit yang telah terimpregnasi Fe, dengan variasi katalis Fe/Zeolit yaitu 1\%, 3\%, 5\%, dan 7\%, dan ukuran 60, 80, 100 mesh, sedang variasi suhu yaitu $250^{\circ} \mathrm{C}$ dan $350^{\circ} \mathrm{C}$, selama $2 \mathrm{jam}$. Hasil yang optimum yang didapat dengan yield terbesar pada penggunaan katalis dengan konsentrasi katalis 3\%, ukuran katalis 60 mesh dan suhu $350^{\circ} \mathrm{C}$. Uji secara fisika yang dilakukan adalah uji specific gravity yaitu sebesar 0,8241 pada yield yang optimum dengan konsentrasi katalis 3\%, dan 1,0392 pada penggunaan katalis dengan konsentrasi 5\%. Dari hasil uji GCMS menunjukkan bahwa komponen yang mendominasi biofuel yang dihasilkan adalah bensin dilihat dari kandungan senyawa C6 sebesar 17,2 \% dan C8 sebesar 13,7\%. Dapat dikatakan jumlah terbesar adalah biogasoline ditunjukkan dengan keberadaan senyawa C5-C11 sebesar 72,4\% dari pada biodiesel ditunjukkan dengan prosentase C12C15 sebesar 24,1\%.
\end{abstract}

Kata kunci: Biofuel; minyak jelantah; catalytic cracking; Fe/zeolite.

\section{PENDAHULUAN}

Biofuel meupakan energi alternatif yang potensial untuk dikembangkan di Indonesia, mengingat Indonesia adalah negara agraris yang memiliki kekayaan keragaman hayati. Biofuel merupakan hasil dari proses pengolahan bahan organik, yang mampu menyerap karbondioksida sebagai penyebab tingginya efek rumah kaca 
/bahan bakar yang ramah lingkungan (Fargione, Hill, Tilman, Polasky, \& Hawthorne, 2008).

Minyak goreng bekas dapat dijadikan alternatif bahan baku untuk produksi bahan bakar nabati. Jelantah merupakan minyak goreng bekas yang telah rusak akibat proses oksidasi, polimerisasi, dan hidrolisis. Ciri-cirinya dapat dilihat dari kenampakan rupa yang kurang menarik dan cita rasa yang tidak enak (Adhani, Aziz, Nurbayti, \& Octavia, 2016). Akibat prosesproses tersebut beberapa trigliserida akan terurai menjadi senyawa - senyawa lain, salah satunya free fatty acid (FFA) atau asam lemak bebas[(Suirta, 2009)]. Menurut Data Statistik Perkebunan Indonesia, jumlah produksi minyak goreng sebesar 35,3 juta ton pertahun dan di Jakarta menyebutkan bahwa 390.000 liter minyak jelantah terbuang setiap bulannya (Soerawidjaja, T.H. 2016).

Asam-asam lemak bebas dengan rantai hidrokarbon panjang dapat dijadikan hidrokarbon yang lebih pendek melalui reaksi pemutusan rantai karbon asam lemak. Cracking merupakan suatu cara untuk memecah rantai molekul hidrokarbon yang besar menjadi molekul yang lebih kecil. Perengkahan ini menggunakan suhu dan tekanan yang tinggi tanpa adanya katalis, atau suhu dan tekanan yang lebih rendah dengan menggunakan katalis. Perengkahan dengan katalis di kenal dengan Catalytic Cracking (Aziz, Adhani, Yolanda, \& Saridewi, 2019).

\section{METODE PENELITIAN}

Penelitian ini memanfaatkan minyak goreng bekas menjadi biofuel dengan cara catalytic cracking menggunakan katalis Fe/Zeolit alam lampung. Yang mendasari penelitian ini adalah penelitian azis I dkk yang melakukan proses catalytic cracking pada minyak jarak dengan katalis zeolite alam lampung untuk menghasilkan biofuel(Aziz et al., 2019) juga penelitian Adhani L yang telah menghasilkan biodiesel dari minyak jelantah(Adhani et al., 2016).

\section{Material}

Minyak jelantah yang dikumpulkan dari penjual kaki lima, zeolit alam yang diperoleh dari PT. Winatama Lampung, Fe (NO3)3 pa , AgNO3 pa, dan $\mathrm{NH} 4 \mathrm{Cl}$ were purchased from Merck.

\section{Instrumentasi}

Alat yang digunakan adalah satu set reaktor catalytic cracking yang serupa dengan satu set alat distilasi laboratorium. Gas Cromatography-Mass Spectroscopy (GC-MS) Agilent Technologies5973 inert, hydrometer DJ1 Standar specific gravity meter small Misumi, termometer dan peralatan gelas.

\section{Prosedur}

Prosedur yang digunakan dalam penelitian ini adalah modifikasi dari penelitian Aziz I (Aziz et al., 2019) dan Adhani L (Adhani et al., 2016).

Timbang minyak jelantah sebanyak 150 gram dan katalis Fe/Zeolit alam lampung dengan variasi konsentrasi $(1,3,5$, dan $7 \%$ dari berat minyak jelantah), serta variasi ukuran katalis (60, 80, dan 100 mesh).

Percobaan dimulai dengan mereaksikan 150 gram minyak jelantah variasi 3\% katalis pada ukuran 60, 80, dan 100 mesh dengan suhu reaksi 250 dan $350^{\circ} \mathrm{C}$ untuk mendapatkan ukuran katalis dan suhu reaksi yang optimum dilihat dari yield yang di dapat. Selanjutnya, proses catalytic cracking dijalankan pada konsentrasi katalis 1, 5, dan $7 \%$.

\section{Karakterisasi senyawa} Analisis senyawa kimia biofuel dengan GC-MS (Kelly \& Bell, 2018)

GC-MS Agilent Technologies-5973 inert digunakan untuk analisis senyawa kimia pada biofuel. Sebanyak $0.1 \mathrm{~mL}$ sampel cair diinjeksikan dengan injector ke dalam kolom melalui injection port. Sampel akan berinteraksi dengan fase diam dalam kolom, kemudian fase gerak akan membawa sampel sampai ke detektor dan menghasilkan kromatogram melalui sistem operasi komputer. Data yang dihasilkan kemudian dibandingkan dengan standar yang ada dalam literatur sehingga dapat ditentukan senyawa kimianya.

Uji Specific Gravity (ASTM D-4052) (D 4052, 2013)

Sampel dimasukkan ke dalam silinder hidrometer. Termometer dicelupkan ke dalam sampel dan dibaca suhunya. Hidrometer dicelupkan ke dalam sampel dan dibaca skala hidrometer yang dipotong oleh permukaan sampel. 


\section{Waktu dan Lokasi Penelitian}

Penelitian ini dilakukan di Laboratorium Kimia Universitas Bhayangkara Jakarta Raya. Untuk Pengujian katalis dan analisis biofuel dilakukan di Puslabfor POLRI, Lemigas dan Puslit Kimia LIPI Serpong. Waktu penelitian dilakukan dalam waktu enam bulan.

\section{HASIL DAN PEMBAHASAN Penentuan Kondisi Optimum}

Penentuan Kondisi optimum proses diawali dengan melihat hasil dari variasi ukuran katalis pada konsentrasi katalis 3\%, dan suhu $250^{\circ} \mathrm{C}$.

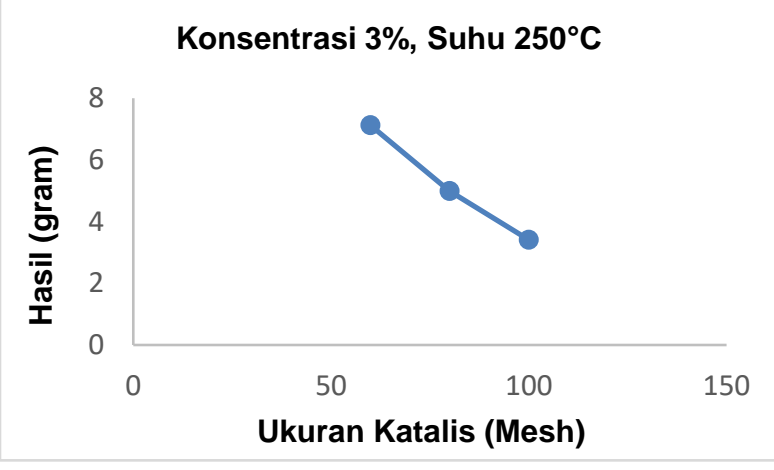

\section{Gambar 1. Pengaruh Ukuran Katalis Terhadap Hasil}

Gambar 1 di atas merupakan grafik ukuran katalis versus hasil yang didapat, grafik tersebut menunjukkan bahwa pada percobaan proses dengan variasi ukuran katalis sebagai variabel berubah, dan variabel tetap yaitu suhu dan konsentrasi katalis, yang memperoleh hasil terbesar adalah ukuran katalis 60 mesh. Hasil reaksi pada ukuran 60 mesh sebesar 7.12 gram, pada ukuran 80 mesh sebesar 4.99 gram, dan pada ukuran 100 mesh sebesar 3.41 gram. Data ini dijadikan acuan untuk percobaan selanjutnya, dimana peneliti akan menggunakan ukuran katalis 60 mesh sebagai variabel tetap.

Selanjutnya dilakukan proses catalytic cracking dengan variasi konsentrasi katalis padaukuran katalis 60 mesh, suhu $350^{\circ} \mathrm{C}$. Grafik pada gambar 2 menunjukkan bahwa percobaan reaksi dengan variasi konsentrasi katalis $1 \%, 3 \%$, $5 \%, 7 \%$, dan ukuran katalis 60 mesh, suhu $350^{\circ} \mathrm{C}$; hasil yang terbesar adalah pada konsentrasi $3 \%$. Maka dapat dikatakan bahwa kondisi optimum proses untuk mendapatkan hasil reaksi yang terbesar pada konsentrasi katalis 3\%, ukuran katalis 60 mesh dan suhu $350^{\circ} \mathrm{C}$.

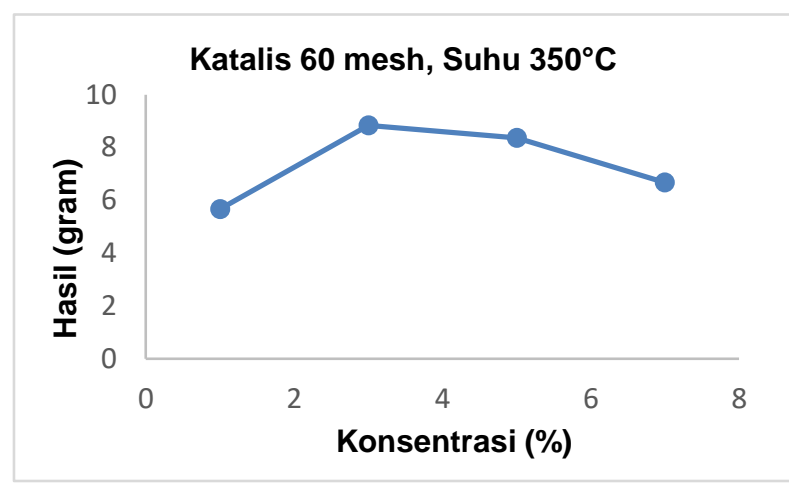

Gambar 2. Pengaruh Konsentrasi Katalis Terhadap Hasil

Analisis senyawa kimia biofuel dengan GC-MS (Kelly \& Bell, 2018)

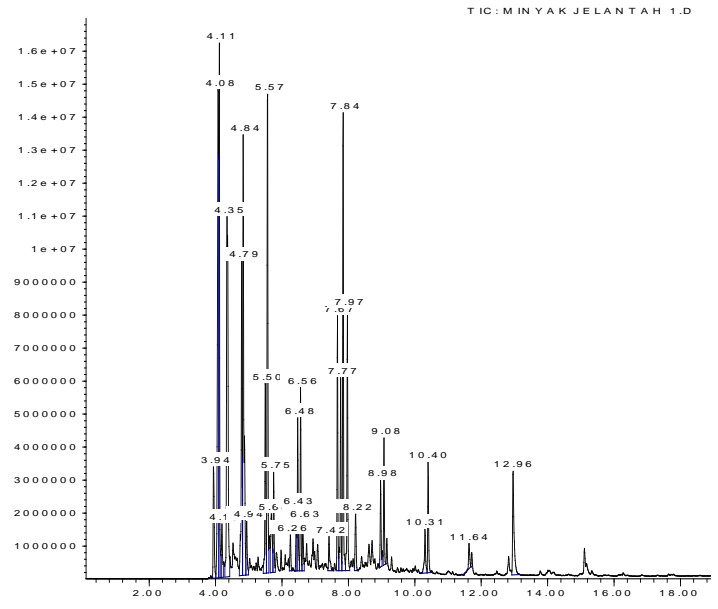

Gambar 3. Hasil Uji GCMS

Dari hasil pengujian GCMS di atas, dapat dilihat bahwa kandungan biofuel dari hasil penelitian ini terdapat senyawa $\mathrm{C}_{5}-\mathrm{C}_{11}$ sebanyak $72.4 \%$, dan senyawa $\mathrm{C}_{12}-\mathrm{C}_{15}$ sebanyak $24.1 \%$. Dimana kandungan dari biofuel tersebut didominasi oleh senyawa alkana dan alkena. Indeks similiaritas pada pengujian GCMS menunjukkan tingkat kemiripan dengan senyawa yang ditentukan. Hal ini menunjukkan bahwa semakin tinggi indeks similiaritas maka semakin presisi hasil yang didapatkan. 
Tabel 4. Senyawa pada Biofuel yang dihasilkan

\begin{tabular}{|c|c|c|c|c|}
\hline Puncak & $\begin{array}{l}\text { Waktu } \\
\text { Retensi }\end{array}$ & $\begin{array}{c}\text { Nama } \\
\text { Senyawa }\end{array}$ & $\begin{array}{c}\text { Rumus } \\
\text { Molekul }\end{array}$ & $\begin{array}{c}\text { Indeks } \\
\text { Similiaritas }\end{array}$ \\
\hline 1 & 3.94 & 2-Propenal & $\mathrm{C}_{3} \mathrm{H}_{4} \mathrm{O}$ & 43 \\
\hline 2 & 4.08 & n-Hexane & $\mathrm{C}_{6} \mathrm{H}_{14}$ & 87 \\
\hline 3 & 4.11 & Hexane & $\mathrm{C}_{6} \mathrm{H}_{14}$ & 91 \\
\hline 4 & 4.19 & Cyclopentane & $\mathrm{C}_{5} \mathrm{H}_{10}$ & 70 \\
\hline 5 & 4.34 & 1-Heptene & $\mathrm{C}_{7} \mathrm{H}_{14}$ & 94 \\
\hline 6 & 4.79 & 1-Octene & $\mathrm{C}_{8} \mathrm{H}_{16}$ & 94 \\
\hline 7 & 4.84 & Octane & $\mathrm{C}_{8} \mathrm{H}_{18}$ & 94 \\
\hline 8 & 4.93 & 2-Octene & $\mathrm{C}_{8} \mathrm{H}_{16}$ & 95 \\
\hline 9 & 5.5 & 1-Nonene & $\mathrm{C}_{9} \mathrm{H}_{18}$ & 95 \\
\hline 10 & 5.57 & Nonane & $\mathrm{C}_{9} \mathrm{H}_{20}$ & 95 \\
\hline 11 & 5.68 & Cyclohexanone & $\mathrm{C}_{6} \mathrm{H}_{10} \mathrm{O}$ & 91 \\
\hline 12 & 5.76 & Cyclooctene & $\mathrm{C}_{8} \mathrm{H}_{14}$ & 97 \\
\hline 13 & 6.26 & Cyclohexane & $\mathrm{C}_{6} \mathrm{H}_{12}$ & 90 \\
\hline 14 & 6.43 & Cyclopentane & $\mathrm{C}_{5} \mathrm{H}_{10}$ & 70 \\
\hline 15 & 6.47 & 1-Decene & $\mathrm{C}_{10} \mathrm{H}_{20}$ & 95 \\
\hline 16 & 6.57 & Decane & $\mathrm{C}_{10} \mathrm{H}_{22}$ & 94 \\
\hline 17 & 6.64 & Cis-4-Decene & $\mathrm{C}_{10} \mathrm{H}_{20}$ & 96 \\
\hline 18 & 7.41 & Benzene & $\mathrm{C}_{6} \mathrm{H}_{6}$ & 64 \\
\hline 19 & 7.67 & Dodecane & $\mathrm{C}_{12} \mathrm{H}_{26}$ & 91 \\
\hline 20 & 7.76 & Undecane & $\mathrm{C}_{11} \mathrm{H}_{24}$ & 95 \\
\hline 21 & 7.84 & 5-Undecene & $\mathrm{C}_{11} \mathrm{H}_{24}$ & 96 \\
\hline 22 & 7.97 & 4-Undecene & $\mathrm{C}_{11} \mathrm{H}_{24}$ & 96 \\
\hline 23 & 8.22 & Cyclopentene & $\mathrm{C}_{5} \mathrm{H}_{8}$ & 64 \\
\hline 24 & 8.98 & 1-Dodecene & $\mathrm{C}_{12} \mathrm{H}_{26}$ & 98 \\
\hline 25 & 9.07 & Dodecane & $\mathrm{C}_{12} \mathrm{H}_{26}$ & 95 \\
\hline 26 & 10.31 & 1-Tridecene & $\mathrm{C}_{13} \mathrm{H}_{26}$ & 97 \\
\hline 27 & 10.41 & Tridecane & $\mathrm{C} 13 \mathrm{H} 28$ & 97 \\
\hline 28 & 11.64 & 2-Tetradecene & $\mathrm{C} 14 \mathrm{H} 28$ & 97 \\
\hline 29 & 12.96 & Pentadecane & $\mathrm{C} 15 \mathrm{H} 32$ & 97 \\
\hline
\end{tabular}

Uji Specific Gravity (SpGr)

Tabel 1. Standar Specific Gravity(Institute, 1969)(ASTM International United States, 2013)

\begin{tabular}{|l|l|}
\hline Componen & Specific Gravity \\
\hline Minyak Ringan & $<0.934$ \\
\hline Minyak Berat & $0.934-1$ \\
\hline Tar & $>1$ \\
\hline
\end{tabular}

Tabel 1 merupakan tabel standar specific gravity yang umum dipakai mengacu pada
American Petroleum Index dan American Society for Testing and Material-D 4052.

Tabel 2. Uji Sampel pada kondisi optimum (3\%, 60 mesh, $350^{\circ} \mathrm{C}$ )

\begin{tabular}{|c|c|c|c|}
\hline Determination & Unit & Result & Method \\
\hline Specific & & & ASTM \\
Gravity at & - & 0.8241 & D. \\
$60 / 60^{\circ} \mathrm{F}$ & & & 4052 \\
\hline
\end{tabular}

Berdasarkan standar specific gravity, hasil uji sampel biofuel dari kondisi optimum dengan konsentrasi 3\%, ukuran katalis 60 mesh dan suhu $350^{\circ} \mathrm{C}$ menunjukkan bahwa biofuel yang diperoleh merupakan termasuk dalam kategori minyak ringan. Dalam golongan minyak bumi, minyak ringan dapat diartikan sebagai minyak yang mengandung kadar logam dan belerang rendah, berwarna terang dan bersifat encer (viskositas rendah). Gasoline / Bensin termasuk dalam golongan minyak ringan.

Tabel 3. Uji Sampel pada kondisi operasi yang mendekati optimum $\left(5 \%, 60\right.$ mesh, $\left.350^{\circ} \mathrm{C}\right)$

\begin{tabular}{|c|c|c|c|}
\hline Determination & Unit & Result & Method \\
\hline Specific & & & ASTM \\
Gravity at & - & 1.0392 & D. 4052 \\
$60 / 60^{\circ} \mathrm{F}$ & & & \\
\hline
\end{tabular}

Berdasarkan standar specific gravity, hasil uji sampel dari konsentrasi katalis 5\% menunjukkan bahwa biofuel yang diperoleh merupakan termasuk dalam kategori tar. Tar adalah cairan berbasis karbon dan hidrokarbon kental yang didapatkan dari berbagai jenis materi organik melalui distilasi destruktif. Hal ini membuktikan bahwa hasil yang didapat pada konsentrasi katalis 5\% bukanlah kondisi operasi yang optimum, walaupun hasil yang didapat besarnya mendekati hasil pada kondisi operasi menggunakan ukuran katalis 3\%.

\section{KESIMPULAN}

Dari hasil penelitian ini, dapat ditarik simpulan bahwa katalis Fe/Zeolit alam lampung efektif untuk dipakai sebagai katalis pada proses catalytic cracking minyak jelantah. Kondisi 
optimum proses catalytic cracking minyak jelantah menggunakan katalis Fe/Zeolit ini, pada konsentrasi katalis 3\%, ukuran katalis 60 mesh, dan suhu reaksi $350^{\circ} \mathrm{C}$.

Produk yang dihasilkan adalah gasoline/ bensin dilihat dari hasil pengujian specific gravity menggunakan sampel optimum (konsentrasi katalis $3 \%$ ) yaitu sebesar 0.8241 yang menurut ASTM D 4052 termasuk dalam kategori minyak ringan.

Pada pengujian analisa GCMS, dapat dilihat bahwa senyawa yang mendominasi kandungan biofuel merupakan senyawa $\mathrm{C}_{5}-\mathrm{C}_{11}$ sebanyak $72.4 \%$, dan senyawa $\mathrm{C}_{12}-\mathrm{C}_{15}$ sebanyak $24.1 \%$. dengan puncak tertinggi $\mathrm{C}_{6}$ yakni sebanyak $17.2 \%$, kemudian senyawa $\mathrm{C}_{8}$ yakni sebanyak $13.7 \%$.

\section{UCAPAN TERIMA KASIH}

Kami ucapkan terimakasih kepada Kementrian Riset dan teknologi Pendidikan Tinggi yang telah membiayai penelitian ini dalam program Hibah Penelitian Dosen Pemula 2019.

\section{DAFTAR PUSTAKA}

Adhani, L., Aziz, I., Nurbayti, S., \& Octavia, C. A. (2016). Pembuatan Biodiesel dengan Cara Adsorpsi dan Transesterifikasi Dari Minyak Goreng Bekas. Jurnal Kimia VALENSI, 2(1), 71-80.

ASTM International United States. (2013). Designation: D 4052 - 96 Standard Test Method for Density, Relative Density, and API Gravity of Liquids by Digital Density Meter 1. ASTM International.

Aziz, I., Adhani, L., Yolanda, T., \& Saridewi, N. (2019). Catalytic cracking of Jatropa curcas oil using natural zeolite of Lampung as a catalyst . IOP Conference Series: Earth and Environmental Science, 299, 012065.

D 4052. (2013). Standard Test Method for Density, Relative Density, and API Gravity of Liquids by Digital Density Meter. ASTM International.

Soerawidjaja,T.H. (2016). Bahan-bahan Bakar
Nabati dan Potensi Produksinya di Indonesia. https://pii.or.id/bahan-bahanbakar-nabati-dan-potensi-produksinya-diindonesia

Fargione, J., Hill, J., Tilman, D., Polasky, S., \& Hawthorne, P. (2008). Land clearing and the biofuel carbon debt. In Science.

Institute, A. P. (1969). Specification for Indirect Type Oil-Field heaters (Seventh Ed.). washington, DC 20005: 12201 Street, Northwest.

Kelly, K., \& Bell, S. (2018). Evaluation of the reproducibility and repeatability of GCMS retention indices and mass spectra of novel psychoactive substances. Forensic Chemistry.

Suirta, I. (2009). Preparasi Biodiesel Dari Minyak Jelantah Kelapa Sawit. Journal of Chemistry, 3(1), 1-6. 